\title{
Fabrication and testing of W7-X pre-series target elements
}

\author{
J Boscary ${ }^{1}$, B Böswirth ${ }^{1}$, H Greuner ${ }^{1}$, P Grigull ${ }^{2}$, M Missirlian ${ }^{4}$, A Plankensteiner ${ }^{3}$, B \\ Schedler $^{3}$, T Friedrich ${ }^{3}$, J Schlosser ${ }^{4}$, B Streibl ${ }^{1}$, H Traxler $^{3}$ \\ ${ }^{1}$ Max-Planck-Institut für Plasmaphysik, EURATOM Association, 85748 Garching, Germany \\ ${ }^{2}$ Max-Planck-Institut für Plasmaphysik, EURATOM Association, 17491 Greifswald, Germany \\ ${ }^{3}$ Plansee SE, Technology Center, 6600 Reutte, Austria \\ ${ }^{4}$ Commissariat à l'Energie Atomique CEA Cadarache, EURATOM Association, 13108 St Paul lez Durance, \\ France \\ jean.boscary@ipp.mpg.de
}

\begin{abstract}
The assembly of the highly-loaded target plates of the WENDELSTEIN 7-X (W7-X) divertor requires the fabrication of 890 target elements. The plasma facing material is made of CFC NB31 flat tiles bonded to CuCrZr copper alloy water-cooled heat sink. The elements are designed to remove a stationary heat flux and power up to $10 \mathrm{MW} / \mathrm{m}^{2}$ and $100 \mathrm{~kW}$, respectively. Before launching the serial fabrication, pre-series activities aimed at qualifying the design, the manufacturing route and the nondestructive examinations. High heat flux tests performed on full-scale pre-series target elements resulted in an improvement of the design of the bond between tiles and heat sink to reduce the stresses during operation. The consequence is the fabrication of additional pre-series target elements to be tested in the high heat flux facility GLADIS. Non-destructive examinations of this bond based on thermography methods are developed to define the acceptance criteria suitable to the serial fabrication.
\end{abstract}

\section{Introduction}

The target plates of the W7-X divertor [1] are designed to remove 10 MW power load for pulse operation up to 30 minutes. The highly-loaded surface of $19 \mathrm{~m}^{2}$ is designed to withstand a maximum stationary heat flux of $10 \mathrm{MW} / \mathrm{m}^{2}$. This surface is achieved by the arrangement of 890 individual target elements (TEs).

Before launching the serial production, a pre-series phase was needed in order to qualify the design, the manufacturing route with the relevant non-destructive examinations (NDEs), and the necessary repairing processes. The validation of the whole package is based on the results of the high heat flux (HHF) tests of full-scale pre-series TEs performed in the GLADIS facility [2]. The elements must withstand loading conditions analogous to those in W7-X without degradation of performance and integrity. The outcome is the definition of the acceptance criteria of a TE suitable to the serial fabrication based on the NDEs and HHF test results . During the pre-series activities, 35 TEs have been delivered (figure 1). Main lessons learnt during the fabrication, examinations and tests of these elements are summarized. HHF test results showed the needs for an improvement of the design. Preseries activities have been extended, and additional TEs have been designed and are currently under manufacture. 


\section{Geometry of TEs and main fabrication steps}

Fourteen types of TEs characterized by a maximum length ranging from 250 to $595 \mathrm{~mm}$, and a maximum width between 50 and $61.5 \mathrm{~mm}$, are to be provided. The slight trapezoidal shaping of TEs varies as a function of the length. To withstand a heat flux of $10 \mathrm{MW} / \mathrm{m}^{2}$ and to remove up to $100 \mathrm{~kW}$ in stationary operation, the selected concept is the bonding of flat tiles made of CFC (carbon fibre reinforced carbon composite) to water-cooled CuCrZr copper alloy heat sink.

The TE fabrication was awarded to the company Plansee SE. The manufacturing route is a parallel processing of different parts, which are assembled in a final stage (figure 2). The critical steps are the manufacture and the inspections of the various bonds:

- active metal casting $\left(\mathrm{AMC}^{\circledR}\right.$ ) between CFC tiles and copper interlayer;

- hot isostatic pressing (HIP) or electron beam welding (EBW) of CFC-AMC ${ }^{\circledR}$ tiles to CuCrZr heat sink;

- EBW between base plate and lid, both made of CuCrZr, to produce heat sinks;

- EBW of the inlet/outlet water-cooling tubes made of CuCrZr on one side to the heat sink, and, on the other side, to the water manifolds made of stainless steel with a transition interlayer made of nickel.

\section{Lessons learnt during the pre-series phase}

\subsection{Fabrication and examinations of the heat sink}

First attempts on samples indicated an unusual higher level of porosity in the CuCrZr welds between the lid and the base plate, which was correlated to the content of cadmium in the CuCrZr raw material. This result shown that the original specified content of $150 \mathrm{ppm}$ had to be decreased and kept at a value lower than $5 \mathrm{ppm}$.

A minimum thickness of $3 \mathrm{~mm}$ of the CuCrZr wall at the outer edges of the heat sink allows a reliable industrial EBW process (figure 3). A blind EBW of the central leg was introduced to increase the stiffness and to ensure the tightness between the adjacent water-channels during operation. To this end, a minimum width of $3 \mathrm{~mm}$ is required at this position. However, the elements are not sufficiently wide to allow the EBW of other legs, and therefore only a mechanical contact at these positions between the base plate and the lid is achievable. No effect of possible by-pass between channels on the cooling performance of the elements was observed during HHF tests. Figure 3 also shows the preserved circular shape of the channel at the end of the fabrication. The twisted tape made of stainless steel with $1 \mathrm{~mm}$ thickness is placed in the straight parts of the channel only. It is mechanically attached at its extremities to the heat sink by a key-slot design. A short wider key of $10.5 \mathrm{~mm}$ is inserted into a slot of a $1 \mathrm{~mm}$ depth machined into the base plate. The diameter of the cooling channel is $9.5 \mathrm{~mm}$. Cutting examinations showed no gap between the channel walls and the tape.

The NDEs performed by Plansee SE to check defective welds are based on the ultrasonic method. This approach was qualified using dedicated probes manufactured with calibrated defects. Finally, the reliability of the examinations throughout the industrial process has been demonstrated since no leak was detected during the inspections before and after HHF tests. The acceptance criteria of the He leak test examination are:

- a leak rate lower than $510^{-7} \mathrm{~Pa} \mathrm{l} / \mathrm{s}$ at room temperature, and $4 \mathrm{MPa}$ internal He pressure;

- a leak rate lower than $510^{-6} \mathrm{~Pa} \mathrm{l} / \mathrm{s}$ at $160^{\circ} \mathrm{C}$ and $2.5 \mathrm{MPa}$ internal He pressure.

For the inlet/outlet cooling tubes, the mechanical tests performed on full-scale probes reached the specification, namely, a tensile strength and a rupture strain higher than $80 \%$ and $50 \%$ of the CuCrZr bulk, respectively. The rupture always occurred in the nickel part. NDEs selected by Plansee SE to inspect this component are the dye penetrating test to detect cracks and x-ray to identify pores. It was demonstrated that all artificial and calibrated defects introduced into dedicated samples were detected by these methods. Finally, no leak was noticed during the final inspections and tests.

Destructive tests performed on some full-scale heat sink probes showed that the burst pressure of the heat sink is higher than $20 \mathrm{MPa}$; this value has to be compared to the operating inlet pressure of water of $2.5 \mathrm{MPa}$.

CFC tiles were removed from some full-scale pre-series TEs. Afterwards TEs were tested on the GLADIS facility to evaluate the thermal limits of the heat sink [3]. A critical heat flux test with a consequent burn-out occurred at an incident heat flux of $31 \mathrm{MW} / \mathrm{m}^{2}$ (axial velocity $=10 \mathrm{~m} / \mathrm{s}$, static 
pressure $=1 \mathrm{MPa}$, inlet temperature $=20^{\circ} \mathrm{C}$ ). The cooling conditions were similar to foreseen operating conditions. This experimental value is higher that the required design value of $25 \mathrm{MW} / \mathrm{m}^{2}$. These tests confirmed the sufficient safety margin for operation in W7-X.

In conclusion, the design and technology together with the NDEs for the fabrication of the heat sink and of the inlet/outlet cooling tubes have been validated for the serial fabrication.

\subsection{Bond of the tiles to the cooling structure}

Pre-series activities [4] and previous projects such as the toroidal pump limiter of Tore Supra [5] confirmed that the reliability of this joint is the key issue of the fabrication.

The first phase was the production of the CFC Sepcarb ${ }^{\circledR}$ NB31 material. Main results of the characterization exhibited a large scatter in the tensile strength in the ex-pitch fibre direction between the three produced batches for W7-X [6]. Due to the reduced strength in the ex-pitch fibre direction, it was necessary to fabricate additional pre-series TE and to perform HHF tests on GLADIS. The results of these tests did not reveal any impact of the CFC batch on the joint quality, using either HIP or EBW. Finally, the delivery was accepted.

The reference process used for the production of the $A M C^{\circledR}$ tiles of the delivered pre-series TEs is the casting of a $3 \mathrm{~mm}$ thick $\mathrm{AMC}^{\circledR}$ copper interlayer. An improvement was achieved by performing this process in presence of silicon in addition. This improvement was demonstrated by a push-test in the shear plane introduced by Plansee SE [7, 8]. The samples showed a measured value of $30 \mathrm{MPa}$ and $60 \mathrm{MPa}$ without and with silicon, respectively. The counterpart is a lower global thermal conductivity of the cast copper, which is reduced by a factor of $\sim 2$ compared to a pure copper layer.

There are two geometries of $\mathrm{AMC}^{\circledR}$ tiles: flat tiles and L-shaped tiles. The latter are placed at the end of the TE which face the pumping space or at the lateral edge along a part of some special diagnostic TEs. About $66 \%$ of the target elements are equipped with such tiles. At these locations, the expected stationary heat flux may reach a maximum value of $3 \mathrm{MW} / \mathrm{m}^{2}$. L-shaped tiles have a $45^{\circ}$ inclination of the carbon fibre planes with respect to the bonding interface. HHF test results performed on GLADIS validated this concept [7]. The casting of the $3 \mathrm{~mm}$ thick $\mathrm{AMC}^{\circledR}$ copper interlayer of the reference design will be used for the serial production of the L-shaped tiles.

An equivalent amount of pre-series TEs was manufactured either by EBW or by HIP. HHF test results did not show any difference in the TE performance between the two technologies. But, these HHF tests exhibited a high percentage of $\sim 15 \%$ of defective tiles after about 100 cycles at $10 \mathrm{MW} / \mathrm{m}^{2}$ for 10s pulse duration each. 70\% (about 150 tiles) showed no defect and the remaining 15\% still require further investigation. The first cycle exhibited $\sim 4 \%$ of defective tiles and $\sim 6 \%$ of questionable tiles. However, the loss of a tile was never observed, even after 1000 cycles at $10 \mathrm{MW} / \mathrm{m}^{2}$.

To improve the design of this interface, simulations of the thermal loading and the subsequent cooling down phase were performed using the finite element method [9]. The goal was to minimize the strain and the stress, while suggesting solutions compatible with an industrial process. At first, the model was validated by showing a good agreement between predictions and measured temperatures and strains during HHF tests on GLADIS [10]. It came out that an adequate solution to reduce the thermal stresses would be the replacement of the interlayer reference design by a bi-layer made of $0,4 \mathrm{~mm}$ thick AMC ${ }^{\circledR}$ copper and a pure copper layer of $2 \mathrm{~mm}$ thick. The AMC ${ }^{\circledR}$ tiles are HIPped together with the copper layer to the heat sink block in one step. For the repairing process, a so-called HIP- AMC ${ }^{\circledR}$ tile (AMC ${ }^{\circledR}$ tile $+2 \mathrm{~mm}$-copper layer) is EBWed to the heat sink. The bend of the AMC $^{\circledR}$ flat tiles can be significantly decreased by reducing its size from $\sim 62 \mathrm{~mm}$ down to $\sim 20 \mathrm{~mm}$. Two or three tiles cover the width of the TE instead of one in the reference design. This solution increases significantly the amount of $\mathrm{AMC}^{\circledR}$ flat tiles to be produced for the serial fabrication. A $90^{\circ}$ shift of in-plane CFC axis between ex-PAN and needled fibres (ex-PAN fibres placed along the element instead of across) is also proposed to get a lower CFC stiffness in the lateral direction. A new set of about 20 pre-series TEs based on these proposals is being fabricated, and will be tested in GLADIS.

\section{Acceptance criteria}

The objective of the pre-series activities is to select the most appropriate NDEs suitable to serial fabrication. The key fabrication step is the bond between tiles and heat sink. The outcome is the definition of the acceptance criteria, which define the maximum acceptable defect (size, shape, 
location) that allows specified operating conditions. It is achieved by the comparison between NDEs and HHF test results.

The NDEs are based on different thermography methods [11]. The ARGUS test facility of Plansee SE is integrated throughout the manufacturing route and exhibits different operation modes. It is performed after each critical step, starting with $\mathrm{AMC}^{\circledR}$ flat tiles. The operational mode of ARGUS is the pulsed thermography mode [12], which provides better readable information than the lock-in thermography mode. The Fast Fourier Transform based data treatment allows the separate inspection of each individual interface, namely, between $\mathrm{AMC}^{\circledR} \mathrm{Cu}$ and $\mathrm{CuCrZr}$ at the appropriate base frequency (the depth of the interface and the required frequency for that depth are known), and between CFC and $\mathrm{AMC}^{\circledR} \mathrm{Cu}$ at the first harmonic frequency. A complementary set-up is the transient thermography of the SATIR facility of CEA, which inspects the whole interface CFC/CuCrZr and is a global thermal hydraulic reception test of the completed TE. The principle is the detection of a delay in the surface temperature evolution introduced by an abrupt variation of the temperature of the water flowing in the cooling channel, which is compared to the response of a reference "defect-free" element. The reliability in the interpretation of the results of NDEs is being improved by the data merging method [13].

These approaches have limitations because they provide an acceptance criterion to characterize only the thermal and not the mechanical performance of the bond. Attempts to check the mechanical performance of the bond using the non-linear vibrometry at different frequencies were not successful until now. Therefore, the reliability of the prediction of these methods is strongly related to a significant margin in the design. Obviously, they cannot detect a thermal / mechanical deficiency of the bond, which is going to appear and grow during the thermal cycling tests. The HHF test results are the reference to judge the quality of the delivered component and the reliability of the NDE predictions; the comprehensive analysis of these data is a key issue.

Assuming a quite flat distribution of the input power, any evolution of the surface temperature (unexpected increase of average temperature, hot spot) during cycling loads indicates a degradation of the bond between the tile and the heat sink. Hot spots appearing on the surface during cycling are usually located at the lateral edge of the tile. In a first case, a hot spot grows together with a delayed cooling down phase. Mostly, the visual examination performed afterwards correlated this event to the initiation and /or propagation of cracks at the interface between CFC and AMC $^{\circledR}$ copper (figure 4). These cracks were not visible during the reception test. A second case is the appearance of a hot spot during the first 25 cycles under $10 \mathrm{MW} / \mathrm{m}^{2}$ typically. It remains stable and, after 100 cycles, no crack is visible at the interface. The interpretation of such hot spot is difficult and the following hypothesis is proposed. CFC is an intrinsically inhomogeneous and anisotropic material. Metallographic examinations showed broken ex-pitch fibres due to the needling process. In addition, Plansee SE has recently observed in some tiles a tilting of the ex-pitch fibres with respect to the bonding interface (figure 5). In this configuration, some fibres are not directly connected to the $A M C^{\circledR}$ copper interface, and consequently may generate hot spot at the edge. First calculations showed a possible increase of the surface temperature up to $15 \%$ at one edge for an inclination of $10^{\circ}$ of the carbon fibre plane with respect to the normal vector of the bonding interface. Metallographic examinations of the tiles showing hot spot during cycling will allow to confirm this hypothesis.

\section{Conclusion}

Pre-series activities confirmed the basic design, the manufacturing route together with the relevant NDEs of the cooling structure for the serial fabrication. This phase also confirmed that the most difficult step in the manufacturing process of the W7-X target elements is the bonding between CFC NB31 flat tiles and CuCrZr heat sink.

The performance of full-scale pre-series TEs has been assessed in the ion beam HHF test facility GLADIS by performing 100 thermal cycles at $10 \mathrm{MW} / \mathrm{m}^{2}$ for 10 seconds pulse duration each. $70 \%$ of the tested tiles showed no defect, $15 \%$ were clearly defective and $15 \%$ still require further investigation. The results of these tests showed the necessity to improve the design of the interface between CFC tiles and CuCrZr heat sink. A comprehensive analysis of the behaviour of this joint during heat loading based on the finite element method enabled the selection of the most effective options with feasible fabrication and qualification efforts. Additional pre-series elements have been 
fabricated and will be tested in GLADIS shortly. Results of these HHF tests and of the NDEs will be carefully analysed before starting the serial fabrication. 


\section{References}

[1] Renner H, Sharma D, Kisslinger J, Boscary J, Grote H, Schneider R 2004 Fus. Sci. Technol. 46 (2) 318

[2] Greuner H, Bolt H, Böswirth B, Franke T, McNeely P, Obermayer S, Rust N, Süß R 2005 Fus. Eng. and Design 75-79 345

[3] Greuner H, Böswirth B, Boscary J, Leuprecht A, Plankensteiner A Power load limits of the WENDELSTEIN 7-X target elements - comparison of experimental results and design values for power loads up to the critical heat flux - this volume

[4] Boscary J, Greuner H, Mendelevitch B, Schedler B, Scheiber K, Schlosser J, Streibl B 2005 Fus. Eng. and Design 75-79 451

[5] Schlosser J, Escourbiac F, Cordier J J, Miteau R, Durocher A, Grosman A 2003 High Heat Flux Testing Impact on the Tore Supra Toroidal Pumped Limiter Achievement Proc. 20th IEEE/NPSS/SOFE, San Diego, USA

[6] Boscary J, Böswirth B, Greuner H, Missirlian M, Schedler B, Scheiber K, Schlosser J, Streibl B Results of the examinations of the W-X pre-series target elements Fus. Eng. and Design at press

[7] Schedler B, Huber T, Eidenberger E, Scheu T, Pippan R, Clemens H Methods to determine the joint strength of C/C to copper joints Fus. Eng. and Design at press

[8] Greuner H, Böswirth B, McNeely P, Boscary J High heat flux facility GLADIS - Operational characteristics and results of W7-X pre-Series target tests - Nucl. Fusion at press

[9] Plankensteiner A, Leuprecht A, Schedler B, Scheiber K, Greuner H Finite element based design optimization of WENDELSTEIN 7-X divertor components under high heat flux loading Fus. Eng. and Design at press

[10] Greuner H, Böswirth B, Boscary J, Plankensteiner A, Schedler B High heat flux tests of the WENDELSTEIN 7-X pre-series target elements -experimental evaluation of the thermo-mechanical behaviour- Fus. Eng. and Design at press

[11] Missirlian M, Traxler H, Boscary J, Durocher A, Schlosser J, Schedler B, Schuler P Infrared thermography inspection methods applied to the target elements of W7-X Divertor Fus. Eng. and Design at press

[12] Traxler H, Schuler P Pulsed Thermography Inspection of the Target Elements for the W7-X Divertor this volume

[13] Durocher A, Moysan J, Escourbiac F, Missirlian M, Vignal N Infrared images data merging for plasma facing component inspection Fus. Eng. and Design at press 


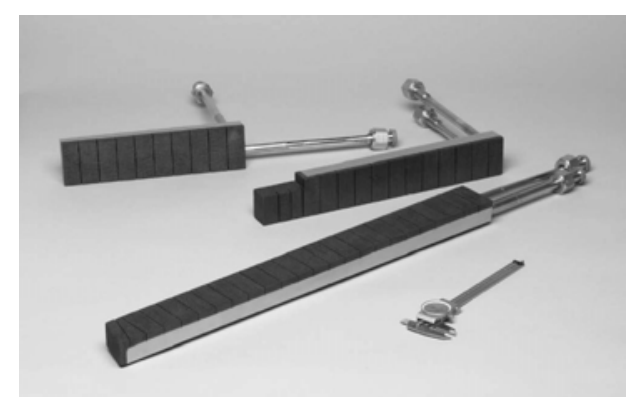

Figure 1: Different types of pre-series TEs

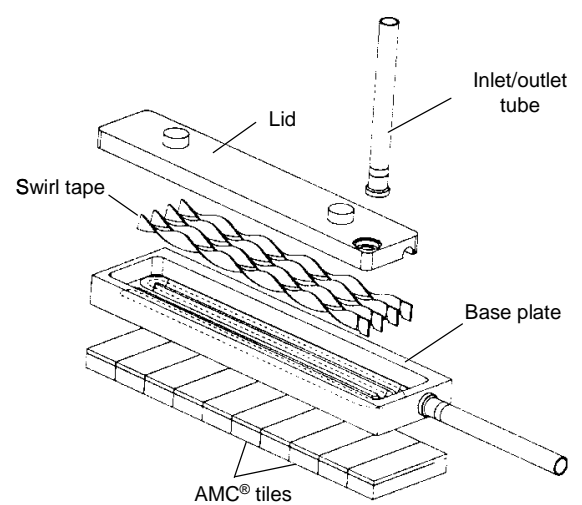

Figure 2: Components of a target element

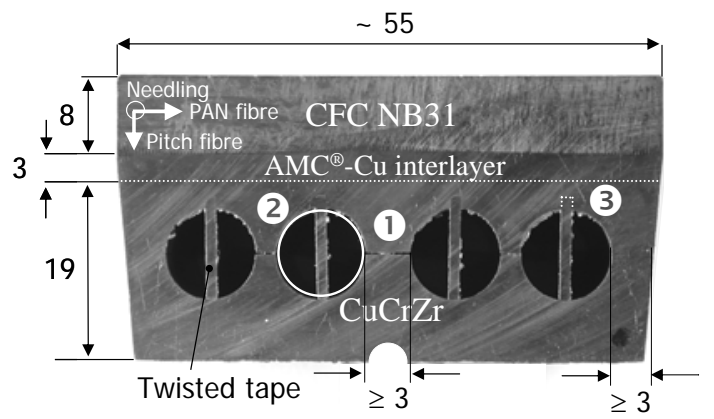

Figure 3: Representative cross-section of a target element (type 4S) - dimensions in mm.

(1: EBW spot in central part.

2: rounded shape of the channel

3: twisted tape insertion in heat sink

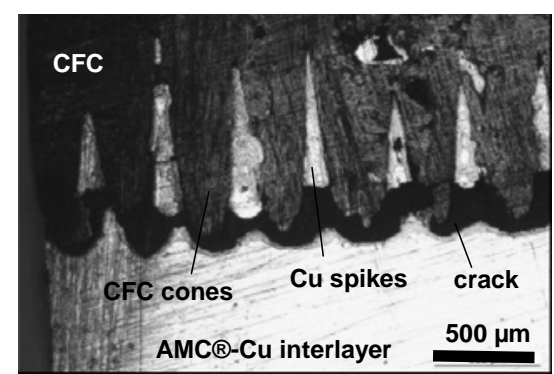

Figure 4: Typical crack propagation at the outer edge after $100 \mathrm{HHF}$ cycling tests at $10 \mathrm{MW} / \mathrm{m}^{2}$. 
Figure 5: Visible inclination of ex-pitch fibres of an $\mathrm{AMC}^{\circledR}$ flat tiles - the tile thickness of $8 \mathrm{~mm}$ is shown. 